\title{
May the force be with you: why resistance training is essential for subjects with type 2 diabetes mellitus without complications
}

\author{
Roberto Codella ${ }^{1,2} \cdot$ Marta Ialacqua $^{1} \cdot$ Ileana Terruzzi ${ }^{3} \cdot$ Livio Luzi $^{1,2}$ \\ Received: 11 March 2018 / Accepted: 13 April 2018 / Published online: 5 May 2018 \\ (c) Springer Science+Business Media, LLC, part of Springer Nature 2018
}

\begin{abstract}
Physical activity, together with diet and pharmacological therapy, represents one of the three cornerstones in type 2 diabetes mellitus treatment and care. The therapeutic appeal of regular physical activity stems from: (i) its non-pharmacological nature; (ii) its beneficial effects on the metabolic risk factors associated with diabetes complications; (iii) its low costs. Evidence accumulated in the last years suggests that aerobic training — endurance training — constitutes a safe modality of intervention, achievable, and effective in diabetes treatment, whenever it is not limited by comorbidities. Aerobic training exerts insulin-mimetic effects and has been shown to lower mortality risk too. Anaerobic, intense physical activity, such as that of strength or power sports disciplines, is not univocally recognized as safe and simple to realize, however, it is important in stimulating energy and glucose metabolism. According to recent evidence, high-intensity training may be prescribed even in the face of cardiovascular diseases, peripheral vascular disease, or osteoarthritis. Some studies have shown resistance training to be more efficient than aerobic exercise in improving glycemic control. This review explores the most up-to-date indications emerging from literature in support of the beneficial effects of strength stimulation and resistance training in patients with type 2 diabetes without complications.
\end{abstract}

Keywords Resistance training $\cdot$ Strength $\cdot$ Type 2 diabetes $\cdot$ Glycemic control

\begin{tabular}{|c|c|}
\hline \multicolumn{2}{|c|}{ Abbreviations } \\
\hline ACSM & American College of Sports Medicine \\
\hline ADA & American Diabetes Association \\
\hline $\mathrm{AE}$ & aerobic exercise \\
\hline AMPK & $\begin{array}{l}\text { phosphorylated adenosine monophosphate- } \\
\text { activated protein kinase }\end{array}$ \\
\hline ATP & adenosine triphosphate \\
\hline AKT & protein kinase $\mathrm{B}$ \\
\hline CaMKII & calmodulin-dependent protein kinase II \\
\hline BMI & body mass index \\
\hline DSME & diabetes self-management education \\
\hline ECG & electrocardiogram \\
\hline ESSA & Exercise and Sport Science Australia \\
\hline GLP-1 & glucagon-like peptide \\
\hline
\end{tabular}

Roberto Codella

roberto.codella@unimi.it

1 Department of Biomedical Sciences for Health, Università degli Studi di Milano, Milan, Italy

2 Metabolism Research Center, IRCCS Policlinico San Donato, San Donato Milanese, Italy

3 Diabetes Research Institute, Metabolism, Nutrigenomics and Cellular Differentiation Unit, San Raffaele Scientific Institute, Milan, Italy

$\begin{array}{ll}\text { GLUT4 } & \text { glucose transporter } 4 \\ \text { GSK3 } \beta & \begin{array}{l}\text { glycogen synthase kinase } 3 \beta \\ \text { HbA1c }\end{array} \\ \text { glycosylated hemoglobin } \\ \text { HDACs } & \begin{array}{l}\text { histone deacetylases } \\ \text { maximum heart rate }\end{array} \\ \text { IRM } & \text { International Diabetes Federation } \\ \text { Ig } & \text { immunoglobuline } \\ \text { IL } & \text { interleukin } \\ \text { LPS } & \text { lipopolysaccharide } \\ \text { MEF2 } & \text { myocite enhancer factor 2 } \\ \text { mTOR } & \text { mammalian target of rapamycin } \\ \text { NAFLD } & \text { nonalcoholic fatty liver disease } \\ \text { PI3K } & \text { phosphatidylinositol } 3 \text { kinase } \\ \text { PGC-1 } \alpha & \text { peroxisome proliferator-activated receptor- } \\ & \text { gamma coactivator 1 } \alpha \\ \text { PRT } & \text { progressive resistance training } \\ \text { 1RM } & \text { one repetition maximum } \\ \text { RT } & \text { resistance training } \\ \text { T1D } & \text { type 1 diabetes } \\ \text { T2D } & \text { type 2 diabetes } \\ \text { TCA } & \text { tricarboxylic acid } \\ \text { TNF } & \text { tumor necrosis factor } \\ \text { TPE } & \text { therapeutic patient education } \\ \text { WHO } & \text { World Health Organization } \\ & \end{array}$

GLUT4 glucose transporter 4

HbA1c glycosylated hemoglobin

HDACs histone deacetylases

HRM maximum heart rate

IDF International Diabetes Federation

Ig immunoglobuline

IL interleukin

LPS lipopolysaccharide

MEF2 myocite enhancer factor 2

mTOR mammalian target of rapamycin

NAFLD nonalcoholic fatty liver disease

PI3K phosphatidylinositol 3 kinase
PGC-1 $\alpha$ peroxisome proliferator-activated receptor- gamma coactivator $1 \alpha$ one repetition maximum resistance training type 1 diabetes type 2 diabetes tricarboxylic acid tumor necrosis factor World Health Organization




\section{Background: the ascertained need of exercise in the management of diabetes}

Diabetes mellitus represents a group of metabolism alterations characterized by chronic hyperglycemia due to defective secretion and/or insulin action, including abnormalities in fat and protein metabolism. When the cause is a regulatory disorder of the immune system (autoimmunity), pancreas either produces low insulin, or insulin is not produced at all; that is type 1 diabetes mellitus (T1D), which comprises $95 \%$ of all pediatric cases. In type 2 diabetes mellitus (T2D), the insulin action, i.e., the response of peripheral tissues to this hormone, is deficient within an insulin resistance context and/or inappropriate insulin secretion.

Often, both problems coexist in the same patient aggravating the syndromic clinical picture.

Diabetes results therefore as a chronic-degenerative metabolic disease that has reached pandemic proportions, mainly because of the increasing incidence and prevalence of T2D. According to the International Federation of Diabetes (IDF, 2017), 425 millions of people suffer from diabetes in the world and these may rise to 629 million in 2045 [1]. About $95 \%$ of known cases of diabetes and virtually all the cases of unknown diabetes are classifiable as T2D. Approximately 5\% of the known cases of diabetes are classifiable as T1D.

Within this epidemiological perspective, diabetes emerges as one of the main metabolic diseases with substantial costs for the European and worldwide sanitary system. Prevention is one of the major international challenges and therapies can luckily leverage on two modifiable risk factors: overnutrition (which leads to obesity) and physical inactivity. The major international medical agencies have claimed physical activity being fundamental against the diffusion of diabetes. According to American Diabetes Association (ADA) and American College of Sports Medicine (ACSM): "Physical exercise performs a primary role in the prevention and control of insulin-resistance, prediabetes, gestational diabetes mellitus, T2D and its complications" [2]. Physical exercise, in fact, is capable to activate acutely glucose metabolism. Ad hoc training programs are effective on stimulating insulin action in the organism of insulin resistant patients, in toto. Uncountable studies show how physical exercise increases glucose uptake at peripheral and systemic level, improves insulin sensitivity, and permits to positively ride the known hyperbolic curve of glucose tolerance [3]. While weight loss and improvement of insulin sensitivity have been positively associated to endurance training $[2,4,5]$ owing to the insulin-mimetics effects of aerobic exercise (AE) in T2D patients, strength exercise and muscular conditioning have been always debated with controversy, mostly in reference to the acute stressors inducing an overload to vascular system, potentially already challenged by long-term hyperglycemic conditions. Recent literature, however, has confirmed the need to integrate training programs with force stimulation, in subjects with T2D, as addressed by several seminal studies-randomized controlled trials-whereby resistance training (RT) resulted to be beneficial under many aspects, even in a single-bout session [6].

\section{Materials and methods}

\section{Literature search strategy}

A systematic literature search was carried out in the Cochrane Library and MEDLINE databases for studies published in English (January 1998 to December 2017) combining the terms "resistance training," "type 2 diabetes," "strength," and "force." We examined reference lists in original articles, reviews, and trials. Study search was performed both electronically and by following up references quoted in relevant paper. Case reports were excluded.

\section{Study selection}

The articles were screened, extracted, and read. The relative findings were classified by: (i) resistance training effects on glycemic control; (ii) resistance training effects on insulin sensitivity; (iii) resistance training effects on cardiometabolic health, including body composition, in healthy, diabetic, and obese subjects; (iv) resistance training effects compared to other modalities of training.

Periods of data collections ranged from 1998 to 2017, obtaining outcomes mostly from human models. A synoptic table of the relevant studies analyzed is offered (Table 1).

\section{Benefits of RT}

Progressive resistance training (PRT) procures improvements in body composition mainly via an increase in lean body mass - that is the metabolic active mass capable to remove glucose from the blood stream, using the glucose substrate to produce energy. PRT has been shown to improve insulin resistance and glycemic control, with a reduction of glycosylated hemoglobin (HbA1c), an increase in muscle mass and/or reducing fat mass [7]. Importantly, these findings are even more impressive when considering that similar reduction of HbAlc was found only in combined pharmacological therapies; in particular when a sulphonylurea (secretagogue) was added to metformin (biguanide). Aerobic activity hardly brings to such increase of lean body mass, and often its practice results 


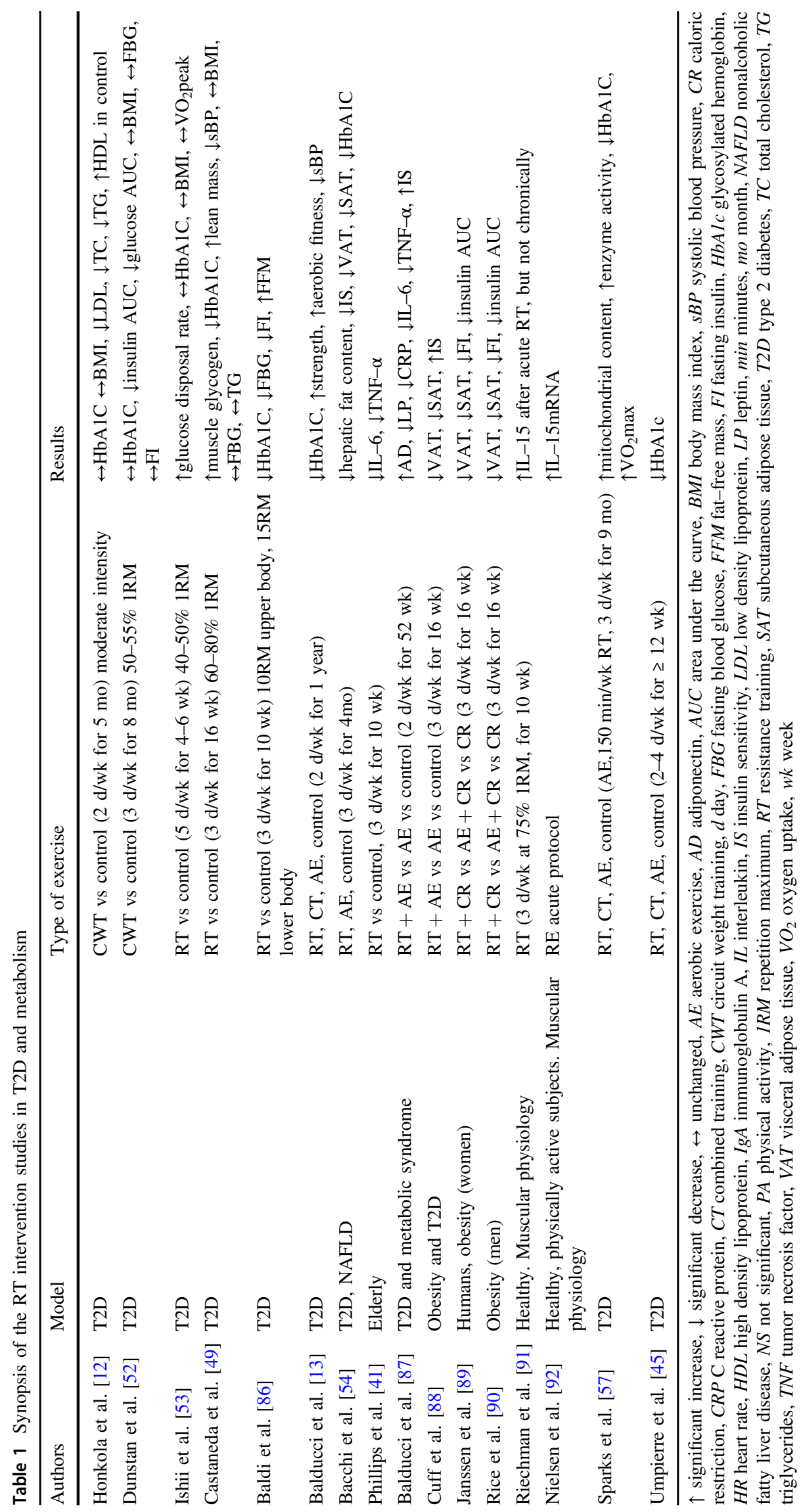


incompatible with several common clinical conditions of people with T2D, aggravated by comorbidities such as obesity, osteoarthritis, peripheral vascular disorders, and other physical disabilities. Paradoxically, in case of these comorbidities, exercise intensity becomes an issue in performing $\mathrm{AE}$ far more than RT. For these subjects, 20-30 min walking can be difficult, harsh, or even painful [8]. In contrast, lifting small weights and anaerobic muscle stimulation, can appear as a valid alternative, leading to metabolic gains that are essential in the management of T2D.

Summarizing, the major benefits documented with RT in subjects with T2D are: (i) increase of insulin sensitivity and glycemic control [9-11]; (ii) improvement of blood cholesterol profiles [12]; (iii) blood pressure decrease [13]; (iv) improvement of cardiac performance; (v) increase in strength and muscular power [14, 15]; (vi) increase of lean body mass [16]; (vii) increase in bone mineral density (with preventive effect on sarcopenia and osteoporosis) [17, 18]; (viii) increase of daily energy expenditure [19, 20], and (ix) quality of life [21].

Nevertheless, differently from aerobic activity (e.g., walking), resistance exercises can require a competent, skilled supervision, the proper execution of training techniques, and handling with a specific equipment.

In this perspective, it is desirable that RT becomes a concrete way, valuable, feasible, and economic, in order to successfully train subjects with T2D. On the other hand, training studies are highly advocated to demonstrate the efficacy of these modalities of intervention, focusing on uncertain factors like intensity and genetic variability for training responsiveness. The ultimate goal would be, for instance, to regulate glucose homeostasis favorably.

Future research strategies and areas should be implemented for an increasingly high number of RT practitioners, giving the great potential of physical activity against the epidemic rising of chronic diseases associated with sedentarism.

\section{International guidelines: recommendations}

Over $60 \%$ of diabetic people do not practice regular physical activity [22]. ADA recommended to subjects with type 2 diabetes at least $150 \mathrm{~min}$ per week of moderate aerobic activity, or $90 \mathrm{~min}$ per week of relevant intensity aerobic activity [23] (Table 2). The Exercise and Sport Science Australia increased previous goals to 210 min per week of moderate activity or 125 min per week of strenuous activity, inclusive of two or more RT sessions [24]. Unfortunately, only $28 \%$ of subjects with T2D meet ADA recommendations [25]. Despite a lifestyle modification of such small entity would significantly impact on cardiometabolic health

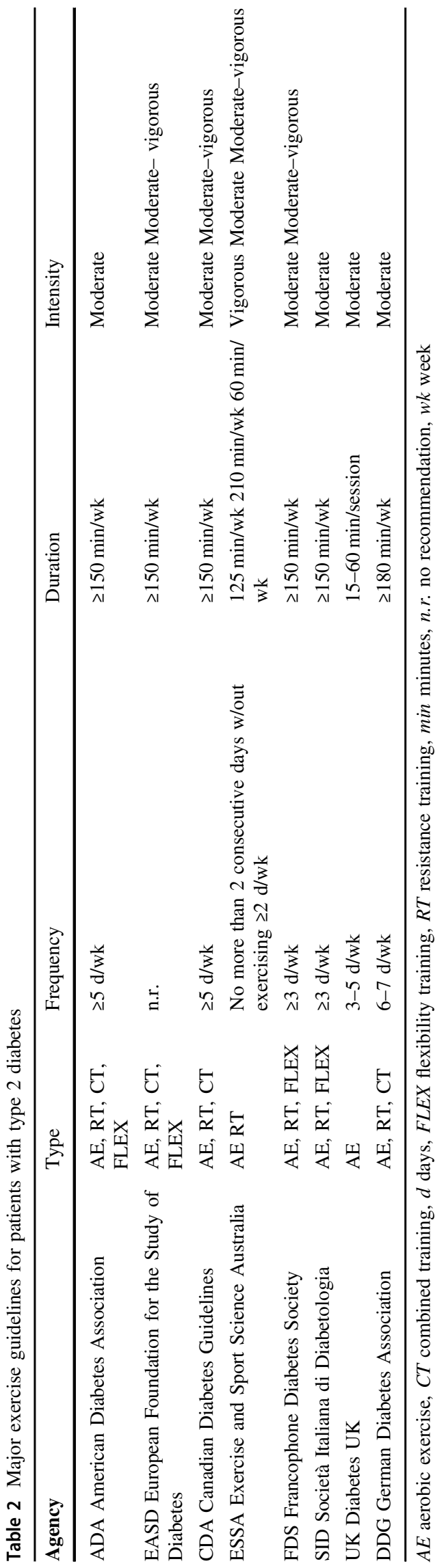


of the population, unfortunately it is unreal that sedentary subjects would be able to respect these guidelines. Thus, it becomes urgent to conceive a training modality practicable for people with T2D.

The ADA and ACSM joint position stand encourages diabetic people to perform RT 2-3 times per week, in nonconsecutive days, focusing on all major (eight) muscle groups [26]. Patients should perform from 5 to 10 exercises including squat, push-up, abdominals, lifts on the ankles, so that all the principal muscle groups would be involved. The ACSM calls to execute 2-3 sets per exercise, from 8 to 10 repetitions each, with a reasonable workload $(75-80 \%$ of one repetition maximum, 1RM). Sessions should be anticipated by $5 \mathrm{~min}$ of warm up, as well as should be followed by a final step of cool down at lower intensity. Untrained subjects could span the work during the day in multiple sessions of shorter duration, in order to reach the predetermined goal with lower fatigue. As to this latter, it would be useful to monitor and quantify the perceived effort with a Borg scale (Borg Rate of Perceived Exertion) [27]. Several devices are also available to manage the cardiovascular intensity, ranging from modern heart rate monitors to smartphone applications, to theoretical algorithms (maximum heart rate, HRM: 220 - age). Moderate intensity should be set as $50-70 \%$ HRM, while vigorous intensity between 70 and $85 \%$ HRM [28]. Obviously, subjects with known cardiovascular problems, autonomic neuropathy, or under beta-blocker regimen, should cautiously modulate and regulate training intensity on predetermined cardiovascular parameters. Abstaining is reasonable, as well as consulting a specialist. An ad hoc visit with diabetologist or sports physician for anamnesis, physical examination, and functional evaluation (resting and exercise electrocardiogram, ECG-test) are therefore strongly recommended before engaging in any physical activity practice [26].

\section{Study outcomes and molecular mechanisms}

In sedentary adults, muscle mass and strength decrease progressively with age, particularly after age of 45 , with a more pronounced reduction following 60-year age [29, 30]. Skeletal muscle tissue-being the first site for glucose and triglycerides disposal-decreases by $3-8 \%$ every decade after the age of 30 [31], increasing the risk of glucose intolerance and T2D pathogenesis, considerably [32]. Diabetes is an independent risk factor for the low-muscular strength [33], and subjects with T2D in old age show an accelerated decline of strength and muscle mass compared with nondiabetic peers $[34,35]$. Epidemiological studies confirm the inverse correlation between muscle strength and metabolic syndrome, and between muscular strength and all-cause mortality [36]. The deleterious loss in lean mass

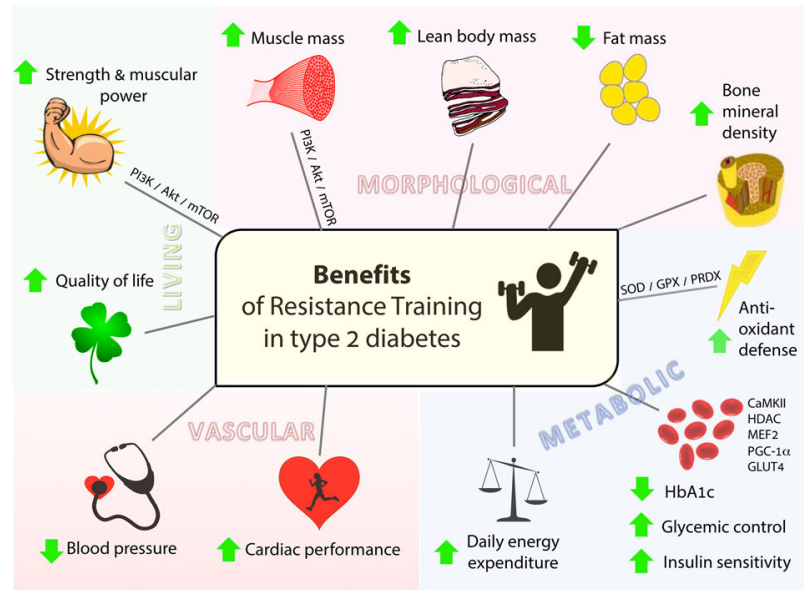

Fig. 1 Depicting overall beneficial adaptive responses of RT in T2D, mediated by peculiar transduction pathways

and muscular strength associated with aging can be exacerbated, in a vicious circle, by progressive physical inactivity. Carrying out activities of daily living (physical independence) and simple motor tasks become harsh, especially for elderly. The muscle of a subject with T2D may be threatened by insulin resistance, impaired glycogenesis, mitochondrial dysfunction, and lipid accumulation [37]. As said, aging per se, is responsible of lean mass loss, however, metabolic and functional disorders can be definitely hindered with strength exercises [38]. A widespread body of evidence points at RT to obtain positive physiological adaptations and unique benefits in T2D (Fig. 1).

In the Health Professional Follow-up Study [39], which monitored more than 32,000 subjects over 18 years, those who trained with RT for more than $150 \mathrm{~min}$ per week showed a $34 \%$ reduction in risk of T2D (normalized for body mass index (BMI) and aerobic activities) [40]. The protection offered by physical activity against T2D increased up to $60 \%$ when the analysis included obese people $(\mathrm{BMI} \geq 30)$ performing RT with $\geq 150 \mathrm{~min} / \mathrm{week}$ [40].

RT can represent an excellent adjuvant in T2D prevention and management by decreasing visceral fat and inflammatory markers [41]. A 3-month program of RT in obese teenagers determined a significant reduction of total and visceral fat, accompanied by an increase of insulin sensitivity compared with nonexercising controls [42]. Some studies have also demonstrated how RTs are effective in reducing abdominal fat in subjects with $\mathrm{T} 2 \mathrm{D}$, even without a weight loss [43]. In the study of Honkola et al. [12], 5 months of PRT in circuit were capable to significantly reduce LDL cholesterol and fasting triglycerides, compared to the control group.

Unanimously, HbA1c is accepted as the most indicative parameter for measuring long-term glycemic control, and is 
strongly associated with diabetes risk, cardiovascular disease, and mortality [44]. RT can improve insulin action and glycemic control in subjects with T2D. In a meta-analysis, Umpierre et al. [45] have reported a reduction of $0.67 \%$ in $\mathrm{Hb} 1 \mathrm{Ac}$ levels in T2D subjects undergone to 12-week RT compared with sedentary controls. In another meta-analysis comprising ten supervised studies, HbA1c decreased by $0.48 \%$ with RT [46]. Most individuals are able to better control their blood glucose levels and body weight [47] via RT-induced increase in lean body mass and insulin sensibility. In particular, RT prevents lean body mass loss in those aiming at weight loss with caloric restriction [38]. Insulin sensitivity and glycemic control can be improved with RT owing to diversified adaptations. The first of these entails the increase of level, density, and translocation of glucose transporter 4 (GLUT4) receptors [48]. Likewise, the protein expression of insulin receptors is increased, with a consequent insulin-sensitizing effect of the training. The improved insulin action is evidenced by the growth in protein-kinase $\mathrm{B}-\alpha / \beta$ content. As an acute training effect, the glucose disposal (glucose clearance) was found accelerated in the leg trained with 6 weeks of RT compared to the non-exercising leg, paralleled by an increase of whole activity and concentration of glycogen synthetase. In another study [49], 16 weeks of supervised, high intensity, PRT, three times per week, increased muscle glycogen storage by $31 \%$ in old subjects with T2D, while controls reported a significance decrease in glycogen content $(-23 \%)$. The PRT-trained group, moreover, reported a decrease of HbAlc from 8.7 to $7.6 \%$. Increasing muscle mass in conjunction with reducing $\mathrm{HbA} 1 \mathrm{c}$ would support the hypothesis according which RTs improve glycemic control by increasing muscle glucose storage [49]. On a singular note, prescribed diabetic medications were reduced in $72 \%$ of the subjects in the PRT group compared with the control group [49].

RT can improve glucose transport in normal and insulinresistant skeletal muscle by activation of the insulin signal pathway [50]. Peculiarly, these RT-induced modifications can improve metabolic profile of skeletal muscle, independently from the increase in lean mass [51].

In one of the first randomized controlled trial, weight lifting at moderate intensity in a circuit training (three times/ week, 55\% 1RM per 8 weeks) showed a decreased insulin response during an oral glucose tolerance test in diabetic patients with respect to controls at rest [52]. During an hyperinsulinemic euglycemic clamp, the glucose disposal was increased by $48 \%$ in T2D subjects trained with 4-6 weeks of moderate-intensity RT, compared to controls, at rest [53].

Recently, Bacchi et al. [54] showed how 4 months of RT and aerobic training were both effective to improve liver fat storage, insulin sensibility, total fat mass and HbAlc in adults with T2D and nonalcoholic fatty liver disease. Ideally, endurance/aerobic training and RT should be combined in order to increase the benefits for subjects with T2D and prediabetes [55]. Positive effects of combined training in subjects with T2D have been demonstrated in several well-sized trials. In the HART-D trial [38], 262 patients with T2D were randomized to four training groups (aerobic, RT, combinated, control) per 3 weekly sessions with the same energy expenditure $(12 \mathrm{kcal} / \mathrm{kg} /$ week $)$ : the best glycemic control was obtained in the combined training group, with an absolute reduction of $0.34 \%$ in HbA1c compared to the other groups. The same design was used in the DARE trial [56] with 251 patients randomized in four groups: the best glycemic control was obtained in the combined training group $(-0.97 \% \mathrm{Hb} 1 \mathrm{Ac}$ vs control). Yet in the DARE trial, the RT group showed further improvements in mental health, vitality and quality-of-life compared to the aerobiconly or control groups. In the IDES Italian study [13], 606 patients with T2D from 22 centers (40-75 years old, HbA1c average levels equal to $7.13 \%$ ) were randomized to two intervention groups: the first group trained in the gym with combined program twice a week with personal trainers' supervision; the second group, as control, self-trained, following a non-supervised program. As a result, the first group observed improvements in all profiles: aerobic fitness, strength, blood pressure, waist circumference, lipids, inflammatory markers, and cardiovascular risk.

The study of Sparks et al. [57] represents the first clear demonstration that RT induces an increase in mitochondrial content in the skeletal muscle of T2D patients trained for 9 months. These adaptations were also associated to other clinical improvements referred to functional performance $\left(\mathrm{VO}_{2} \max \right)$ and glycemic control (HbA1c). The other subjects of the same study were randomized to the aerobic training group, combined, or to nonexercising controls. The combined training group improved, amongst others, all the markers of long- and medium-chain fatty acid oxidation, increased tricarboxylic acid (TCA) cycle flux, as well as mitochondrial content and enzymatic activity. Overall, a number of studies have confirmed a synergistic, addictive effect of combined training ( $\mathrm{RT}+\mathrm{AE}$ ) on glycemic control (up to $-1.5 \%$ in HbA1c) [58], insulin action, exercise tolerance and muscular capacity, in the long term.

RT augments excess oxygen delivery post-training (EPOC, Excess Postexercise Oxygen Consumption) [59]. This increase in oxygen uptake $\left(\mathrm{VO}_{2}\right)$, following a $\mathrm{RT}$ session is consistent with the energy expenditure rise in the recovery period. EPOC suggests an accelerated fat metabolism, which is determinant for weight loss. EPOC seems to be higher in RT compared to aerobic training [60]. Anyway, the increase of energy expenditure, either depending on EPOC or RT, is of pivotal importance to initiate an overall healthful metabolism. 
Hereby the macro-molecular steps describing major phenomena induced by RT.

\section{Hypertrophy}

One of the main metabolic pathways responsible for muscle hypertrophy through the increased protein synthesis would be the IGF-1/PI3K/AKT pathway. AKT stimulates protein synthesis by the mammalian target of rapamycin (mTOR) [61]. In addition to the increase of the skeletal muscle transverse section and muscular mass, RT induces also a shift in the muscle fibers composition. From a histochemical standpoint, RTs would switch $2 \times$ fibers with low oxidative capacity to type 2 a fibers, with a moderate oxidative capacity, these latter surely resulting more insulin-sensitive compared to the former ones [62] (Fig. 2). Altogether, these adaptations result in enhanced skeletal muscle quantity, quality (the amount of muscular strength/torque per unit of regional muscle mass), and function, i.e., muscle strength and power, and motor unit recruitment.

\section{Metabolic control: glycemic control and insulin sensitivity}

There are several adaptations through which regular RT may improve overall glycemic control (possibly even more than what AE can do) and insulin sensitivity: other than increasing GLUT4 levels, RT can augment protein kinase $\mathrm{B}$, insulin receptors, muscle glycogen stores, glycogen synthase, and glycogen synthase total activity following acute training [48]. Recently, it was demonstrated that RT increased glycemic control in part by enhancing microvascular blood flow and substrate delivery to myocytes [63].

Although an enhancement in insulin action is usually related to greater skeletal muscle mass, insulin sensitivity may increase due to RT-procured qualitative changes, regardless of muscle mass gains. For instance, calmodulin-

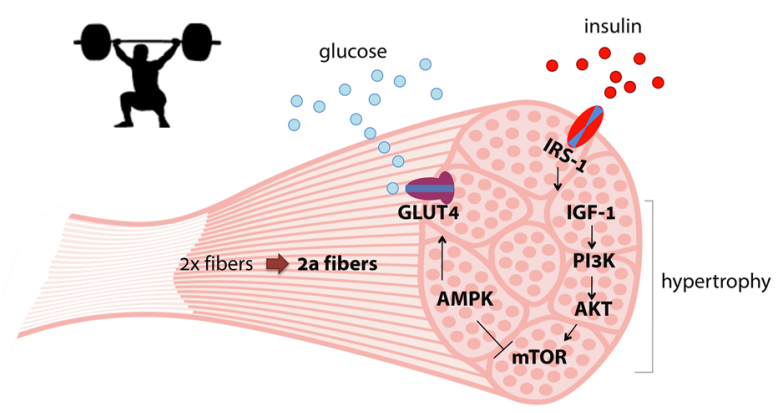

Fig. 2 Molecular mechanisms by which strength stimulation may improve metabolic health in skeletal muscle of patients with T2D.

$\longrightarrow$ Activation/phosphorylation. $\_\mid$Inhibition. $\square$ Shift dependent protein kinase II (CaMKII) is stimulated in an exercise-intensity fashion, and it phosphorylates transcription factors like histone deacetylases (HDACs), which in turn leads to activation of transcription factors such as myocyte enhancing factor 2 (MEF2) and its target genes (PGC-1 $\alpha$, GLUT4) thus ameliorating glycemic control.

In a meta-analysis [64], intensity resulted to be more important than duration in enhancing insulin sensitivity. However, conclusive results are still lacking about the RT effects of different durations/intensities on muscle mass.

\section{Glucose clearance}

Non-oxidative glucose disposal occurs as RT stimulates glycogen synthesis through AKT-mediated glycogen synthase activity. Specifically, RT activates AKT, which, in turn, can inhibit glycogen synthase kinase $3 \beta$ (GSK3 $\beta$ ). Inhibition of GSK3 promotes stimulation of glycogen synthase, therefore leading to the production of glycogen.

It has also been observed an increased activity of AMPK (phosphorylated adenosine monophosphate-activated protein kinase) as an acute phenotypic response to RT [65]. This activation inhibits mTOR signal that impedes protein synthesis during RT (Fig. 2). Transient AMPK activation can induce phosphorylation of target proteins involved in several metabolic pathways. Ultimately this can increase adenosine triphosphate (ATP) production with a higher glucose uptake due to an intensified GLUT4 translocation or lipid oxidation [66]. RT may lead to other adaptations with insulin-mimetics effects: increased fatty acid metabolism (metabolic flexibility) [67] or augmented protein expression of insulin receptors in response to exercise [48].

\section{Mitochondrial capacity}

Mitochondrial dysfunction has been associated to aging and insulin resistance. Subjects with T2D have lowered mitochondrial oxidative capacity, with disrupted mitochondrial morphology a reduction in mitochondrial size. However, skeletal muscle oxidative capacity may be preserved in elderly as in young people, by performing regular, intense physical activity. Limited studies demonstrated the capability of RT in increasing mitochondrial oxidative capacity in healthy individuals. In the study of Sparks et al. [57], a 9month RT program led to an increase in mitochondrial content in the skeletal muscle of T2D patients. Pesta et al. [68] showed that lean subjects had the same increase in mitochondrial respiration in skeletal muscle, following either 10-week RT or AE.

Aging per se leads to sarcopenic alterations of the skeletal muscle, nevertheless physical activity, and especially RT, can help maintain mito-functional and metabolic properties (oxidative) of the muscular tissue. 


\section{Which types of RT?}

$\mathrm{RT}$, as a synonymous of strength training, refers to using muscular contraction to move a load (including a natural one, like one's own body weight), to win a physical resistance: the most common use of opposing muscle contraction-to resist-is against gravity, elastic, or hydraulic forces. RT consists therefore in brief repetitive exercises with free weights (dumbbells and barbells), weight machines, resistance bands, isometric exercises, calisthenics mobilizing one's own body weight (e.g., pushups) to increase muscle strength and/or muscle endurance.

Performing whatever form of RT is important in T2D not only because of the aforementioned health benefits, but also because diabetic subjects are likely to be overweight or obese and therefore they are harshly able to fulfill the recommended doses of "effective" AE. Short and intense RT exercises, repeated manifold throughout the day, should be more feasible and similarly beneficial for these individuals. In the study of Hamasaki et al. [69], 12 weeks of lowintensity RT with slow movement and tonic force generation decreased body fat mass and body fat percentage in 50years old obese subjects with T2D. In addition, muscle mass resulted increased, as well as lipidemic profiles ameliorated. Decreases in fat mass of $1-4.5 \mathrm{~kg}$ were achieved with RT, while AE can lower fat mass of a couple of kilograms, in a typical training program. Diminishing visceral adipose tissue is critical considering the associated chronic low-grade inflammation and cardiometabolic risks. RT appears most beneficial if performed in the long run, at high intensity. However, together with frequency and duration, this is still a matter of debate. In fact, a clear-cut dose dependency is undefined in the increasingly growing body of literature. In the discussed RT programs in T2D, a duration greater than or equal of 12 weeks, along with an estimated intensity ranging from 60 to $80 \%$ of $1 \mathrm{RM}$, were shown sufficient to gain a $10-20 \%$ improvement in muscle mass, insulin sensitivity, body composition, and cardiovascular health. Typically these studies concern RT carried out with weight machines, free weights, and they cannot be generalized to other types of RT, such as resistance bands or exercises utilizing only one's own body weight. For these reasons, tailored RT programs, considering individual crucial factors (level of strength—or 1RM; BMI, physical fitness, severity of diabetes, medications, comorbidities, etc.), are urgently needed.

Supervision of expert personnel (diabetologists, healthcare providers, fitness professionals), within an omnicomprehensive educational approach, may represent a successful intervention strategy. Supervised exercise was shown to be more effective than self-reported physical activity in the compliance of the programs. Qualified trainers, by means of skilled competences and high-quality counseling, can exert a tremendous impact on these health measures, boosting the potential of RT, while minimizing the risks of adverse effects.

In conclusion, investigating the minimum effective dose of beneficial, customized RTs, is the key for the long-term adherence of individuals with T2D (and/or obesity), and for most of the people too.

\section{Therapies combining RT and antidiabetic medications}

A complex variety of factors must be medically addressed when prescribing RT in patients with $\mathrm{T} 2 \mathrm{D}$ or prediabetes: severity of diabetes, duration of the disease, presence of comorbidities, regimens of multiple oral hypoglycemic agents and differently-acting insulins, intensity of strength training. High-intensity efforts may cause a robust depletion of muscle glycogen, therefore exposing patients to the risk of late-onset hypoglycemia, especially under poorly controlled circumstances. Nevertheless, intermittent highintensity exercise was preferred over continuous moderate intensity $\mathrm{AE}$ in order to reduce glycemic excursions posteffort [70]. Blood glucose levels should be carefully managed prior to the initiation of any type of exercise training. Likewise, time of medications and meals ought be properly adjusted for a safe and effective RT participation.

Metformin, one of the most prescribed biguanide-the first-line oral anti-hyperglycemic medication recommended by ADA-has been shown to have pleiotropic effects similar to exercise. In fact, they both independently activate AMPK, therefore increasing insulin-stimulated glucose uptake. It is worth noting that, the magnitude of the RTeffect on HbA1c reduction $(-0.34 \% \leq x \leq-0.57 \%)[45,71]$ is averagely inferior than the one procured by metformin $(-0.97 \%)$ [71] or acarbose $(-0.77 \%)$ [72]. These observations led to hypothesis that combining metformin with exercise would have synergistic effects on insulin sensitivity. On the contrary, according to certain studies, metformin plus exercise did not show addictive effects with respect to exercise alone in improving insulin sensitivity or HbA1c, in both nondiabetic and T2D individuals [73]. Yet, an extent exists, although unknown, by which metformin alters the beneficial effects of exercise in lowering CVD risk in diabetic people. It is possible that metformin triggers distinct adaptations within pancreatic beta cells and, primarily, in the liver. Conversely, metformin plus exercise seem to have addictive effects when weight loss is the outcome considered. Literature findings remain inconsistent and they need to be pursued sistematically. Besides, the majority of these studies have covered endurance training, which may rely much more on the AMPK signaling pathway than RT. 
Another possible explanation is that ROS generation during exercise is a signal for the enhancement of insulin action [73]. Metformin opposes ROS signaling, thus blunting, to some extent, the beneficial adaptations procured by exercise (mitochondrial biogenesis, endothelial function, glucose uptake).

Hence, a doubly positive action coming from the proposition of exercise in conjunction with other compounds (either a drug or an antioxidant/ergogenic/dietary supplement) should be cautiously inferred.

Structured research should test diversified RT intensities and duration in the context of controlled diet and medications. The ultimate goal of combined strategies would be to maximize the metabolic health responses, on a personalized level.

\section{Comprehensive educational programs in the management and care of patients with T2D}

RT prescriptions alone are insufficient to modify, on the long term, the lifestyles of people living with T2D, especially if worsened by overweight and obesity. Barriers do exist for these subjects to comply with structured exercise: these individuals are generally unaccustomed to exercise, with a relevant history of sedentary behavior [74]. Therefore, exercise recommendations need to be personalized on the actual subjects' capabilities. Besides, in order to maximize the exercise benefits, recommendations should be incorporated into comprehensive educational programs, including multifactorial behavioral interventions. The glycemic benefits of RT can be, in fact, quite modest (an approximate decline in $\mathrm{HbAlc}$ of $0.5 \%$ ), thus exercise cannot represent the sole "advocated" intervention, but it should be an adjunctive to both nutritional and medical therapies. Furthermore, when the disease is exacerbated by complications, a therapeutic patient education (TPE) is urgently needed in order to crucially prevent and reduce fatal events (mostly because of cardiovascular events) [75, 76] and the overall disability-free life expectancy. These education programs can have a greater effect on disabilityfree years than total life expectancy, among adults with diabetes [77]. A TPE entails all necessary skills a patient may need to cope with a chronic disease [75]. Several structured TPE programs have been outlined in the management of diabetes. Diabetes self-management education (DSME) embraces peculiar themes concerning basic knowledge on diabetes, physical activity, diet, diabetic medications, self-care, and decision making, while living with the disease [78-80]. These programs have been shown to be fundamental not only in the management of diabetes, but also in the prevention to develop it, or to develop its complications. In fact, complications are approximately four times more frequent in diabetic people with no education respect to patients exposed to educational programs [81]. When TPEs are delivered at individual level, the effects are greater in improving diabetes knowledge, metabolic parameters, and quality of life with respect to group-TPE [82]. Again, all these aspects, as essential part of DSME-from medical nutrition therapy to exercise prescriptions-are more effective when they are "personalized," according to the economic and cultural status of the individuals [2].

Even in the management of T1D, omnicomprehensive programs are capable to optimize and maintain positive metabolic outcomes, also assisted by telemedicine and diversified tele-health care systems [74, 83-85].

In summary, a multifaceted educational plan is highly warranted in diabetic people, firstly to acquire an adequate knowledge on various diabetes themes, and ultimately to gain a greater potential from active lifestyles, improving metabolic and psychosocial outcomes, and therefore reducing disability, morbidity, and mortality.

\section{Conclusive comments}

RT can improve glucose tolerance and insulin sensitivity by qualitative modifications independently of the muscle mass increase. It is well known, however, that insulin sensitivity is directly proportional to lean body mass. The increase of lean mass remains, therefore, a reasonable goal for T2D subjects performing RT: this increase is de facto accompanied by an enhancement of basal metabolism triggering a virtuous cycle (of metabolic health).

It is a vivid interest to consider strength stimulation among the diverse modalities of training doable by T2D subjects. In today's society, so committed in multiplying chances of being physically active, short-repeated exercise is a viable alternative to the traditional high-volume endurance training. High-intensity/low-volume RTs can be efficient strategies to obtain metabolic benefits. The beneficial effects of RT are achievable not only by T2D subjects, but also by a large part of society, maintaining a musculoskeletal health, independence in daily living activities, therefore reducing injury risks and the deleterious effects of aging (sarcopenia).

Funding This research did not receive any specific grant from funding agencies in the public, commercial, or not-for-profit sectors.

Author contributions All authors were responsible for drafting the manuscript and revising it critically for valuable intellectual content. All authors approved the version to be published.

\section{Compliance with ethical standards}

Conflict of interest The authors declare that they have no conflict of interest. 


\section{References}

1. International Diabetes Federation (IDF), World diabetic prevalence (2017)

2. S.R. Colberg, R.J. Sigal, J.E. Yardley, M.C. Riddell, D.W. Dunstan, P.C. Dempsey, E.S. Horton, K. Castorino, D.F. Tate, Physical activity/exercise and diabetes: a position statement of the american diabetes association. Diabetes Care 39, 2065-2079 (2016)

3. S.E. Kahn, R.L. Prigeon, D.K. Mcculloch, E.J. Boyko, R.N. Bergman, M.W. Schwartz, J.L. Neifing, W.K. Ward, J.C. Beard, J. P. Palmer, D. Porte Jr, Quantification of the relationship between insulin sensitiyity and P-cell function in human subjects evidence for a hyperbolic function with a regulated feedback loop control system such that for any difference in $\mathrm{s}$, a proportionate reciprocal difference. Diabetes 42, 1663-1672 (1993)

4. R. Mendes, N. Sousa, A. Almeida, P. Subtil, F. Guedes-Marques, V.M. Reis, J.L. Themudo-Barata, Exercise prescription for patients with type 2 diabetes - a synthesis of international recommendations: narrative review: table 1. Br. J. Sports Med. 50, 1379-1381 (2016)

5. J.A. Dugan, Exercise recommendations for patients with type 2 diabetes. J. Am. Acad. Physician Assist. 29, 13-18 (2016)

6. M.J. Armstrong, R.J. Sigal, Exercise as medicine: key concepts in discussing physical activity with patients who have type 2 diabetes. Can. J. Diabetes 39, S129-S133 (2015)

7. Y. Mavros, S. Kay, K.A. Anderberg, M.K. Baker, Y. Wang, R. Zhao, J. Meiklejohn, M. Climstein, A. O'Sullivan, N. de Vos, B. T. Baune, S.N. Blair, D. Simar, K. Rooney, N. Singh, M.A. Fiatarone Singh, Changes in insulin resistance and HbAlc Are related to exercise-mediated changes in body composition in older adults with type 2 diabetes: interim outcomes from the GREAT2DO trial. Diabetes Care 36, 2372-2379 (2013)

8. N.D. Eves, R.C. Plotnikoff, Resistance training and type 2 diabetes: considerations for implementation at the population level. Diabetes Care 29, 1933-1941 (2006)

9. J. Eriksson, J. Tuominen, T. Valle, S. Sundberg, A. Sovijärvi, H. Lindholm, J. Tuomilehto, V. Koivisto, Aerobic endurance exercise or circuit-type resistance training for individuals with impaired glucose tolerance? Horm. Metab. Res. 30, 37-41 (1998)

10. W.J. Miller, W.M. Sherman, J.L. Ivy, Effect of strength training on glucose tolerance and post-glucose insulin response. Med. Sci. Sports Exerc. 16, 539-543 (1984)

11. E.T. Poehlman, R.V. Dvorak, W.F. DeNino, M. Brochu, P.A. Ades, Effects of resistance training and endurance training on insulin sensitivity in nonobese, young women: a controlled randomized trial. J. Clin. Endocrinol. Metab. 85, 2463-2468 (2000)

12. A. Honkola, T. Forsen, J. Eriksson, Resistance training improves the metabolic profile in individuals with type 2 diabetes. Acta Diabetol. 34, 245-248 (1997)

13. S. Balducci, S. Zanuso, A. Nicolucci, P. De Feo, S. Cavallo, P. Cardelli, S. Fallucca, E. Alessi, F. Fallucca, G. Pugliese, Effect of an intensive exercise intervention strategy on modifiable cardiovascular risk factors in subjects with type 2 diabetes mellitus: a randomized controlled trial: the Italian Diabetes and Exercise Study (IDES). Arch. Intern. Med. 170, 1794-1803 (2010)

14. D.L. Hare, T.M. Ryan, S.E. Selig, A.M. Pellizzer, T.V. Wrigley, H. Krum, Resistance exercise training increases muscle strength, endurance, and blood flow in patients with chronic heart failure. Am. J. Cardiol. 83, 1674-1677 (1999)

15. M.M. Ouellette, N.K. LeBrasseur, J.F. Bean, E. Phillips, J. Stein, W.R. Frontera, R.A. Fielding, High-Intensity resistance training improves muscle strength, self-reported function, and disability in long-term. Stroke 35, 1404-1409 (2004)
16. A.S. Ryan, D.E. Hurlbut, M.E. Lott, F.M. Ivey, J. Fleg, B.F. Hurley, A.P. Goldberg, Insulin action after resistive training in insulin resistant older men and women. J. Am. Geriatr. Soc. 49, 247-253 (2001)

17. M.E. Nelson, M.A. Fiatarone, C.M. Morganti, I. Trice, R.A. Greenberg, W.J. Evans, Effects of high-intensity strength training on multiple risk factors for osteoporotic fractures. a randomized controlled trial. JAMA 272, 1909-1914 (1994)

18. B.F. Hurley, S.M. Roth, Strength training in the elderly. Sports Med. 30, 249-268 (2000)

19. P.A. Ades, Resistance training increases total daily energy expenditure in disabled older women with coronary heart disease. J. Appl. Physiol. 98, 1280-1285 (2005)

20. G.R. Hunter, C.J. Wetzstein, D.A. Fields, A. Brown, M.M. Bamman, Resistance training increases total energy expenditure and free-living physical activity in older adults. J. Appl. Physiol. (1985) 89, 977-984 (2000)

21. R.D. Reid, H.E. Tulloch, R.J. Sigal, G.P. Kenny, M. Fortier, L. McDonnell, G.A. Wells, N.G. Boulé, P. Phillips, D. Coyle, Effects of aerobic exercise, resistance exercise or both, on patientreported health status and well-being in type 2 diabetes mellitus: a randomised trial. Diabetologia 53, 632-640 (2010)

22. E.H. Morrato, J.O. Hill, H.R. Wyatt, V. Ghushchyan, P.W. Sullivan, Physical activity in U.S. adults with diabetes and at risk for developing diabetes, 2003. Diabetes Care 30, 203-209 (2007)

23. S.R. Colberg, R.J. Sigal, B. Fernhall, J.G. Regensteiner, B.J. Blissmer, R.R. Rubin, L. Chasan-Taber, A.L. Albright, B. Braun, Exercise and type 2 diabetes: the American College of Sports Medicine and the American Diabetes Association: joint position statement executive summary. Diabetes Care (2010). https://doi. org $/ 10.2337 / \mathrm{dc} 10-1548$.

24. M.D. Hordern, D.W. Dunstan, J.B. Prins, M.K. Baker, M.A.F. Singh, J.S. Coombes, Exercise prescription for patients with type 2 diabetes and pre-diabetes: a position statement from exercise and sport science Australia. J. Sci. Med. Sport 15, 25-31 (2012)

25. R.C. Plotnikoff, L.M. Taylor, P.M. Wilson, K.S. Courneya, R.J. Sigal, N. Birkett, K. Raine, L.W. Svenson, Factors associated with physical activity in canadian adults with diabetes. Med. Sci. Sports Exerc. 38, 1526-1534 (2006)

26. R.J. Sigal, G.P. Kenny, D.H. Wasserman, C. Castaneda-Sceppa, R.D. White, Physical activity/exercise and type 2 diabetes: a consensus statement from the american diabetes association. Diabetes Care 29, 1433-1438 (2006)

27. G. Borg, Perceived exertion as an indicator of somatic stress. Scand. J. Rehabil. Med. 2, 92-98 (1970)

28. M.J. Karvonen, E. Kentala, O. Mustala, The effects of training on heart rate; a longitudinal study. Ann. Med. Exp. Biol. Fenn. 35, 307-315 (1957)

29. I. Janssen, S.B. Heymsfield, Z. Wang, R. Ross, Skeletal muscle mass and distribution in 468 men and women aged 18-88 Yr. J. Appl. Physiol. 89, 81-88 (2000)

30. J.O. Holloszy, The biology of aging. Mayo Clin. Proc. 75, S3-S8 (2000). Suppl

31. J. Lexell, C.C. Taylor, M. Sjöström, What is the cause of the ageing atrophy? total number, size and proportion of different fiber types studied in whole vastus lateralis muscle from 15- to 83year-old men. J. Neurol. Sci. 84, 275-294 (1988).

32. P. Srikanthan, A.L. Hevener, A.S. Karlamangla, Sarcopenia exacerbates obesity-associated insulin resistance and dysglycemia: findings from the National Health and Nutrition Examination Survey III. PLoS ONE (2010). https://doi.org/10.1371/journal. pone. 0010805 .

33. M. Nishitani, K. Shimada, S. Sunayama, Y. Masaki, A. Kume, K. Fukao, E. Sai, H. Yamashita, H. Ohmura, T. Onishi, M. Shioya, H. Sato, A. Shimada, T. Yamamoto, A. Amano, H. Daida, Impact of diabetes on muscle mass, muscle strength, and exercise 
tolerance in patients after coronary artery bypass grafting. J. Cardiol. 58, 173-180 (2011)

34. S. Park, B. Goodpaster, J. Lee, L. Kuller, R. Boudreau, N. De Rekeneire, T. Harris, S. Kritchevsky, F. Tylavsky, M. Nevitt, Y. Cho, A. Newman, Excessive loss of skeletal muscle mass in older adults with type 2 diabetes. Diabetes Care 32, 1993-1997 (2009)

35. M. Leenders, L.B. Verdijk, L. van der Hoeven, J.J. Adam, J. van Kranenburg, R. Nilwik, L.J.C. Van Loon, Patients with type 2 diabetes show a greater decline in muscle mass, muscle strength, and functional capacity with aging. J. Am. Med. Dir. Assoc. 14, 585-592 (2013)

36. J.R. Ruiz, X. Sui, F. Lobelo, J.R. Morrow, A.W. Jackson, M. Sjostrom, S.N. Blair, Association between muscular strength and mortality in men: prospective cohort study. BMJ 337, a439-a439 (2008)

37. K.F. Petersen, D. Befroy, S. Dufour, J. Dziura, C. Ariyan, D.L. Rothman, L. DiPietro, G.W. Cline, G.I. Shulman, Mitochondrial dysfunction in the elderly: possible role in insulin resistance. Science 300, 1140-1142 (2003)

38. T.S. Church, S.N. Blair, S. Cocreham, W. Johnson, K. Kramer, C. R. Mikus, V. Myers, M. Nauta, R.Q. Rodarte, L. Sparks, A. Thompson, C.P. Earnest, Effects of aerobic and resistance training on hemoglobin A1c levels in patients with type 2 diabetes: a randomized controlled trial. JAMA 304, 2253-2262 (2010)

39. P. Koh-Banerjee, N.F. Chu, D. Spiegelman, B. Rosner, G. Colditz, W. Willett, E. Rimm, Prospective study of the association of changes in dietary intake, physical activity, alcohol consumption, and smoking with 9-y gain in waist circumference among 16587 US men. Am. J. Clin. Nutr. 78, 719-727 (2003)

40. A. Grnøtved, E.B. Rimm, W.C. Willett, L.B. Andersen, F.B. Hu, A prospective study of weight training and risk of type 2 diabetes mellitus in men. Arch. Intern. Med. 172, 1306-1312 (2012)

41. M.D. Phillips, M.G. Flynn, B.K. McFarlin, L.K. Stewart, K.L. Timmerman, Resistance training at eight-repetition maximum reduces the inflammatory milieu in elderly women. Med. Sci. Sports Exerc. 42, 314-325 (2010)

42. S.J. Lee, F. Bacha, T. Hannon, J.L. Kuk, C. Boesch, S. Arslanian, Effects of aerobic versus resistance exercise without caloric restriction on abdominal fat, intrahepatic lipid, and insulin sensitivity in obese adolescent boys a randomized, controlled trial. Diabetes 61, 2787-2795 (2012)

43. J. Ibáñez, M. Izquierdo, C. Martínez-Labari, F. Ortega, A. Grijalba, L. Forga, F. Idoate, M. García-Unciti, J.M. Fernández-Real, E.M. Gorostiaga, Resistance training improves cardiovascular risk factors in obese women despite a significative decrease in serum adiponectin levels. Obesity (Silver Spring) 18, 535-541 (2010)

44. C.J. Currie, J.R. Peters, A. Tynan, M. Evans, R.J. Heine, O.L. Bracco, T. Zagar, C.D. Poole, Survival as a function of $\mathrm{HbA}(1 \mathrm{c})$ in people with type 2 diabetes: a retrospective cohort study. Lancet 375, 481-489 (2010)

45. D. Umpierre, C.K. Kramer, C.B. Leita, J.L. Gross, J.P. Ribeiro, B. D. Schaan, Physical activity advice only or structured exercise training and association with $\mathrm{HbA} 1 \mathrm{c}$ levels in type 2 diabetes. JAMA 305, 1790-1799 (2011)

46. B. Strasser, U. Siebert, W. Schobersberger, Resistance training in the treatment of the metabolic syndrome: a systematic review and meta-analysis of the effect of resistance training on metabolic clustering in patients with abnormal glucose metabolism. Sports Med. 40, 397-415 (2010)

47. M.A. Williams, W.L. Haskell, P.A. Ades, E.A. Amsterdam, V. Bittner, B.A. Franklin, M. Gulanick, S.T. Laing, K.J. Stewart, Resistance exercise in individuals with and without cardiovascular disease: 2007 update: a scientific statement from the American Heart Association Council on clinical cardiology and council on nutrition, physical activity, and metabolism. Circulation 116, 572-584 (2007)
48. M.K. Holten, M. Zacho, M. Gaster, C. Juel, J.F.P. Wojtaszewski, F. Dela, Strength training increases insulin-mediated glucose uptake, GLUT4 content, and insulin signaling in skeletal muscle in patients with type 2 diabetes. Diabetes 53, 294-305 (2004)

49. C. Castaneda, J.E. Layne, L. Munoz-Orians, P.L. Gordon, J. Walsmith, M. Foldvari, R. Roubenoff, K.L. Tucker, M.E. Nelson, A randomized controlled trial of resistance exercise training to improve glycemic control in older adults with type 2 diabetes. Diabetes Care 25, 2335-2341 (2002)

50. B.B. Yaspelkis, Resistance training improves insulin signaling and action in skeletal muscle. Exerc. Sport. Sci. Rev. 34, 42-46 (2006)

51. J.L. Kuk, K. Kilpatrick, L.E. Davidson, R. Hudson, R. Ross, Whole-body skeletal muscle mass is not related to glucose tolerance or insulin sensitivity in overweight and obese men and women. Appl. Physiol. Nutr. Metab. 33, 769-774 (2008)

52. D.W. Dunstan, I.B. Puddey, L.J. Beilin, V. Burke, A.R. Morton, K.G. Stanton, Effects of a short-term circuit weight training program on glycaemic control in NIDDM. Diabetes Res. Clin. Pract. 40, 53-61 (1998)

53. T. Ishii, T. Yamakita, T. Sato, S. Tanaka, S. Fujii, Resistance training improves insulin sensitivity in NIDDM subjects without altering maximal oxygen uptake. Diabetes Care 21, 1353-1355 (1998)

54. E. Bacchi, C. Negri, G. Targher, N. Faccioli, M. Lanza, G. Zoppini, E. Zanolin, F. Schena, E. Bonora, P. Moghetti, Both resistance training and aerobic training reduce hepatic fat content in type 2 diabetic subjects with nonalcoholic fatty liver disease (the RAED2 randomized trial). Hepatology 58, 1287-1295 (2013).

55. B. Strasser, D. Pesta, Resistance training for diabetes prevention and therapy: experimental findings and molecular mechanisms. Biomed. Res. Int. (2013). https://doi.org/10.1155/2013/805217.

56. R.J. Sigal, G.P. Kenny, N.G. Boulé, G.A. Wells, D. Prud'homme, M. Fortier, R.D. Reid, H. Tulloch, D. Coyle, P. Phillips, A. Jennings, J. Jaffey, Effects of aerobic training, resistance training, or both on glycemic control in type 2 diabetes: a randomized trial. Ann. Intern. Med. 147, 357-369 (2007)

57. L.M. Sparks, N.M. Johannsen, T.S. Church, C.P. Earnest, E. Moonen-Kornips, C. Moro, M.K.C. Hesselink, S.R. Smith, P. Schrauwen, Nine months of combined training improves ex vivo skeletal muscle metabolism in individuals with type 2 diabetes. J. Clin. Endocrinol. Metab. 98, 1694-1702 (2013)

58. M. Röhling, C. Herder, M. Roden, T. Stemper, K. Müssig, Effects of long-term exercise interventions on glycaemic control in type 1 and type 2 diabetes: a systematic review. Exp. Clin. Endocrinol. Diabetes 124, 487-494 (2016)

59. K. Osterberg, C. Melby, Effects of acute resistance exercise on postexercise oxigen consumption and resting metabolic rate in young women. Int. J. Sport. Nutr. Exerc. Metab. 10, 71-81 (2000)

60. M.J. Ormsbee, J.P. Thyfault, E.A. Johnson, R.M. Kraus, M.D. Choi, R.C. Hickner, Fat metabolism and acute resistance exercise in trained men. J. Appl. Physiol. (1985) 102, 1767-1772 (2007)

61. S. Schiaffino, C. Mammucari, Regulation of skeletal muscle growth by the IGF1-Akt/PKB pathway: insights from genetic models. Skeletal Muscle (2011). https://doi.org/10.1186/20445040-1-4.

62. M.A. Tresierras, G.J. Balady, Resistance training in the treatment of diabetes and obesity: mechanisms and outcomes. J. Cardiopulm. Rehabil. Prev. 29, 67-75 (2009)

63. R.D. Russell, D. Hu, T. Greenaway, S.J. Blackwood, R.M. Dwyer, J.E. Sharman, G. Jones, K.A. Squibb, A.A. Brown, P. Otahal, M. Boman, H. Al-Aubaidy, D. Premilovac, C.K. Roberts, S. Hitchins, S.M. Richards, S. Rattigan, M.A. Keske, Skeletal muscle microvascular-linked improvements in glycemic control 
from resistance training in individuals with type 2 diabetes. Diabetes Care 40, 1256-1263 (2017)

64. N.G. Boulé, G.P. Kenny, E. Haddad, G.A. Wells, R.J. Sigal, Meta-analysis of the effect of structured exercise training on cardiorespiratory fitness in type 2 diabetes mellitus. Diabetologia 46, 1071-1081 (2003)

65. H.C. Dreyer, S. Fujita, J.G. Cadenas, D.L. Chinkes, E. Volpi, B.B. Rasmussen, Resistance exercise increases AMPK activity and reduces 4E-BP1 phosphorylation and protein synthesis in human skeletal muscle. J. Physiol. 576, 613-624 (2006)

66. J. Mu, J.T. Brozinick, O. Valladares, M. Bucan, M.J. Birnbaum, A role for AMP-activated protein kinase in contraction- and hypoxia-regulated glucose transport in skeletal muscle. Mol. Cell 7, 1085-1094 (2001)

67. L. Xu, M. Ash, S. Abdel-Aleem, J.E. Lowe, M. Badr, Hyperinsulinemia Inhibits hepatic peroxisomal $\beta$-oxidation in rats. Horm. Metab. Res. 27, 76-78 (1995)

68. D. Pesta, F. Hoppel, C. Macek, H. Messner, M. Faulhaber, C. Kobel, W. Parson, M. Burtscher, M. Schocke, E. Gnaiger, Similar qualitative and quantitative changes of mitochondrial respiration following strength and endurance training in normoxia and hypoxia in sedentary humans. Am. J. Physiol. Regul. Integr. Comp. Physiol. 301, R1078-R1087 (2011)

69. H. Hamasaki, Y. Kawashima, Y. Tamada, M. Furuta, H. Katsuyama, A. Sako, H. Yanai, Associations of low-intensity resistance training with body composition and lipid profile in obese patients with type 2 diabetes. PLoS ONE 10, e0132959 (2015)

70. K.E. Iscoe, M.C. Riddell, Continuous moderate-intensity exercise with or without intermittent high-intensity work: effects on acute and late glycaemia in athletes with type 1 diabetes mellitus. Diabet. Med. 28, 824-832 (2011)

71. H. Ishiguro, S. Kodama, C. Horikawa, K. Fujihara, A.S. Hirose, R. Hirasawa, Y. Yachi, N. Ohara, H. Shimano, O. Hanyu, H. Sone, In search of the ideal resistance training program to improve glycemic control and its indication for patients with type 2 diabetes mellitus: a systematic review and meta-analysis. Sports Med. 46, 67-77 (2016)

72. F.A. van de Laar, P.L. Lucassen, R.P. Akkermans, E.H. van de Lisdonk, G.E. Rutten, C. van Weel, Alpha-glucosidase inhibitors for patients with type 2 diabetes: results from a cochrane systematic review and meta-analysis. Diabetes Care 28, 154-163 (2005)

73. S.K. Malin, B. Braun, Impact of metformin on exercise-induced metabolic adaptations to lower type 2 diabetes risk. Exerc. Sport. Sci. Rev. 44, 4-11 (2016)

74. R Codella, I Terruzzi, L Luzi. Treatment of Diabetes with Lifestyle Changes: Physical Activity. Diabetes. Epidemiology, Genetics, Pathogenesis, Diagnosis, Prevention, and Treatment. Springer: Cham, 2018; 1-14.

75. A. Coppola, L. Sasso, A. Bagnasco, A. Giustina, C. Gazzaruso, The role of patient education in the prevention and management of type 2 diabetes: an overview. Endocrine 53, 18-27 (2016)

76. C. Gazzaruso, M. Fodaro, A. Coppola, Structured therapeutic education in diabetes: is it time to re-write the chapter on the prevention of diabetic complications? Endocrine 53, 347-349 (2016)

77. E.W. Gregg, J. Lin, B. Bardenheier, H. Chen, W.J. Rejeski, X. Zhuo, A.L. Hergenroeder, S.B. Kritchevsky, A.L. Peters, L.E. Wagenknecht, E.H. Ip, M.A. Espeland, Look AHEAD Study Group, Impact of intensive lifestyle intervention on disability-free life expectancy: the look AHEAD study. Diabetes Care 14, 172110 (2018)
78. X. He, J. Li, B. Wang, Q. Yao, L. Li, R. Song, X. Shi, J. Zhang, Diabetes self-management education reduces risk of all-cause mortality in type 2 diabetes patients: a systematic review and meta-analysis. Endocrine 55, 712 (2017)

79. L. Haas, M. Maryniuk, J. Beck, C.E. Cox, P. Duker, L. Edwards, E.B. Fisher, L. Hanson, D. Kent, L. Kolb, S. McLaughlin, E. Orzeck, J.D. Piette, A.S. Rhinehart, R. Rothman, S. Sklaroff, D. Tomky, G. Youssef, 2012 Standards Revision Task Force National standards for diabetes self-management education and support. Diabetes Care 37, S144-S153 (2014).

80. American Diabetes Association, 3. Foundations of care and comprehensive medical evaluation. Diabetes Care 39, S23-S35 (2016)

81. A. Nicolucci, D. Cavaliere, N. Scorpiglione, F. Carinci, F. Capani, G. Tognoni, M.M. Benedetti, A comprehensive assessment of the avoidability of long-term complications of diabetes. A casecontrol study. SID-AMD Italian Study Group for the Implementation of the St. Vincent Declaration. Diabetes Care 19, 927-933 (1996)

82. J. Sperl-Hillen, S. Beaton, O. Fernandes, A. Von Worley, G. Vazquez-Benitez, E. Parker, A. Hanson, J. Lavin-Tompkins, P. Glasrud, H. Davis, K. Adams, W. Parsons, C.V. Spain, Comparative effectiveness of patient education methods for type 2 diabetes. Arch. Intern. Med. 171(22), 2001 (2011)

83. M. Adamo, R. Codella, F. Casiraghi, A. Ferrulli, C. Macrì, E. Bazzigaluppi, I. Terruzzi, L. Inverardi, C. Ricordi, L. Luzi, Active subjects with autoimmune type 1 diabetes have better metabolic profiles than sedentary controls. Cell Transplant. 26, 23-32 (2017)

84. R. Codella, M. Adamo, P. Maffi, L. Piemonti, A. Secchi, L. Luzi, Ultra-marathon $100 \mathrm{~km}$ in an islet-transplanted runner. Acta Diabetol. 54(7), 703-706 (2017)

85. R. Codella, I. Terruzzi, L. Luzi, Why should people with type 1 diabetes exercise regularly? Acta Diabetol. 54(7), 615-630 (2017)

86. J.C. Baldi, N. Snowling, Resistance training improves glycaemic control in obese type 2 diabetic men. Int. J. Sports Med. 24, 419-423 (2003)

87. S. Balducci, S. Zanuso, A. Nicolucci, F. Fernando, S. Cavallo, P. Cardelli, S. Fallucca, E. Alessi, C. Letizia, A. Jimenez, F. Fallucca, G. Pugliese, Anti-inflammatory effect of exercise training in subjects with type 2 diabetes and the metabolic syndrome is dependent on exercise modalities and independent of weight loss. Nutr. Metab. Cardiovasc. Dis. 20, 608-617 (2010)

88. D.J. Cuff, G.S. Meneilly, A. Martin, A. Ignaszewski, H.D. Tildesley, J.J. Frohlich, Effective exercise modality to reduce insulin resistance in women with type 2 diabetes. Diabetes Care 26, 2977-2982 (2003)

89. I. Janssen, A. Fortier, R. Hudson, R. Ross, Effects of an energyrestrictive diet with or without exercise on abdominal fat, intermuscular fat, and metabolic risk factors in obese women. Diabetes Care 25, 431-438 (2002)

90. B. Rice, I. Janssen, R. Hudson, R. Ross, Effects of aerobic or resistance exercise and/or diet on glucose tolerance and plasma insulin levels in obese men. Diabetes Care 22, 684-691 (1999)

91. S.E. Riechman, Association of interleukin-15 protein and interleukin-15 receptor genetic variation with resistance exercise training responses. J. Appl. Physiol. 97, 2214-2219 (2004)

92. A.R. Nielsen, R. Mounier, P. Plomgaard, O.H. Mortensen, M. Penkowa, T. Speerschneider, H. Pilegaard, B.K. Pedersen, Expression of interleukin-15 in human skeletal muscle - effect of exercise and muscle fibre type composition. J. Physiol. 584, 305-312 (2007) 